\title{
Problems and Suggestions on Safety Management of Small and Medium Sized Enterprises Based on Inspection Practice
}

\author{
Xiaofeng Zhang ${ }^{1,2}$, Lianghai $\mathrm{Lv}^{1,2}$, Renfeng Tang ${ }^{1,2}$,Yongqiang Bai ${ }^{1,2}$ \\ ${ }^{1}$ Beijing Municipal Institute of Labour Protection, Beijign 100054, China \\ ${ }^{2}$ Beijing Key Laboratory of Control Technology for Toxic, Hazardous, Flammable and Explosive \\ Sources of City ,Beijing 100054, China
}

\section{基于检查实践的中小企业安全生产管理问题与 建议

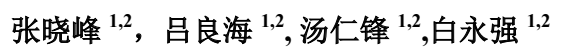 \\ ${ }^{1}$ 北京市劳动保护科学研究所, 北京 100054 , 中国 \\ ${ }^{2}$ 城市有毒有害易燃易爆危险源控制技术北京市重点实验室，北京 100054 , 中国
}

\begin{abstract}
Small and medium-sized enterprises are an important part of China's economy. They play an important role in China's economic construction. The safety is first is the necessary condition to ensure them orderly development. The first, the safety management characteristics of small and medium enterprises are analyzed in this paper. The second, some important problems and hidden danger are list. At the same time, the reasons why these problems and hidden danger happen are discussed. Lastly, some suggestions are put forward from the point of the safety supervision and service. All of these analyses are based on security checks of 300 enterprises. It is of great significance to find out the problems in safety management and take corresponding measures.
\end{abstract}

Keywords:smalland medium-sized enterprises; problems and hidden danger; supervision and service.

\begin{abstract}
摘要
中小企业是我国经济体的重要组成部 分, 在我国经济建设中起着不容忽视的作 用, 而 “安全第一” 是确保其有序发展的 必要条件。本文在对 300 余家中小企业实 地安全检查的基础上, 对中小企业安全生 产特点进行了分析, 从安全生产体系、现 场安全管理等方面对其存在的突出问题和 隐患进行了列举, 对其产生原因进行了论 证, 并从安全生产监管和服务角度提出了 相关的建议。
\end{abstract}

关键词: 中小企业; 问题和隐患; 监管和 服务

\section{1. 引言}

安全生产是衡量国家现代文明程度的 重要指标, 近年来, 我国安全生产形势总 体趋于稳定, 表现在事故总量下降 ${ }^{[1]}$ 。中小 企业在我国国民经济和社会发展中占有重 要的地位, 体现在创造巨大的经济效益, 促进出口贸易, 以及拓宽就业渠道等多个 方面, 中小企业的安全生产持续健康发展, 是安全生产管理工作中, 绝对不容忽视的。 但中小企业规模上相对较小, 与中小企业 
相对安全并不成正比关系。表 1 中所罗列 的中小企业均造成了重大的人员伤亡。因 此, 要从根本上遏制安全生产事故的发生, 绝对不能抓大放小遏制特别重大事故的发 生, 不仅仅要对龙头企业、规模企业进行 严格管控, 小企业的安全生产工作绝对不 容忽视。因此, 实事求是, 结合了解中小 企业实际现状, 发现其安全生产管理中的 问题, 并采取相应的措施, 具有重要的意 义 $^{[2][3]}$ 。

\begin{tabular}{|c|c|c|c|}
\hline $\begin{array}{l}\text { 序 } \\
\text { 号 }\end{array}$ & 时间 & 事故类型 & 后果 \\
\hline 1 & 2011. 4. 25 & $\begin{array}{l}\text { 北京市大兴区旧 } \\
\text { 宫镇服装厂火灾 }\end{array}$ & $\begin{array}{l}18 \text { 人死, } \\
24 \text { 人伤 }\end{array}$ \\
\hline 2 & 2013. 8. 31 & $\begin{array}{l}\text { 上海市上海翁牌 } \\
\text { 冷藏实业有限公 } \\
\text { 司发生液氨泄漏 }\end{array}$ & $\begin{array}{l}15 \text { 人死, } \\
25 \text { 人伤 }\end{array}$ \\
\hline 3 & 2014.2 .5 & $\begin{array}{l}\text { 广东惠东县义务 } \\
\text { 商品城发生火灾 }\end{array}$ & $\begin{array}{l}17 \text { 人死, } \\
4 \text { 人伤 }\end{array}$ \\
\hline 4 & 2014. 12. 31 & $\begin{array}{l}\text { 广东省佛山市广 } \\
\text { 东顺德机械制造 } \\
\text { 工厂发生天然气 } \\
\text { 爆炸事故 }\end{array}$ & $\begin{array}{l}18 \text { 人死, } \\
30 \text { 余人伤 }\end{array}$ \\
\hline 5 & 2016. 4. 29 & $\begin{array}{l}\text { 广东省深圳市精 } \\
\text { 艺星五金加工厂 } \\
\text { 发生铝粉尘爆炸 } \\
\text { 事故 }\end{array}$ & $\begin{array}{l}4 \text { 人死, } 6 \\
\text { 人伤 }\end{array}$ \\
\hline 6 & 2017. 11. 18 & $\begin{array}{l}\text { 北京市大兴区西 } \\
\text { 红门镇公寓楼 }\end{array}$ & $\begin{array}{l}19 \text { 人死, } \\
8 \text { 人伤 }\end{array}$ \\
\hline
\end{tabular}

\section{2. 对象和方法}

\section{1 对象}

本次检查主要依托于安全生产标准化 的现场评审工作。评审工作的开展对象共 涵盖了工程建设类、工业生产类、人员聚 集类、道路交通类、其他类五大类 46 小类 的 300 家中小企业。

\section{2 方法}

检查内容主要依据该地区安全生产标 准化评审标准, 包括安全生产基础管理和 安全生产现场两大模块, 涵盖企业资质、 安全生产管理组织机构、安全生产责任制、
应急管理、职业卫生、消防、用电、特种 设备等安全生产各个要素。

\section{3. 结果分析}

\section{1 中小企业安全生产管理经营特点分析}

(1) 数量巨大, 涉及面广

据统计, 我国现阶段工商注册的中小 企业占全部注册企业总数的 $99 \%$, 数量巨 大, 且分布在城镇、乡村等各个区域, 安 全生产监管力量相对不足。同时, 中小企 业的生产经营内容基本涵盖了社会生活的 方方面面, 涉及到了人员、用电、消防、 特种设备、危险化学品、职业卫生等各类 安全生产要素, 存在的安全生产风险更是 千差万别。本文调查的 300 家企业分布, 入表 2 中。

\section{（2）安全管理决策权高度集中}

对于中小企业, 企业主要负责人往往 对于企业的经营管理具有独一的, 完全的 决策权。因此, 在安全生产管理领域, 主 要负责人的安全意识, 对安全生产工作的 重视程度很大程度上决定了企业安全生产 基础管理体系、风险识别、隐患排查整改、 安全生产资金投入、事故应急等安全生产 工作的开展和落实情况。

（3）人员流动性大

诸多中小企业由于对专业技术性要求 较弱, 很多工作经过短时期的培训即可正 式上岗, 且由于中小企业在薪酬待遇方面 缺乏足够的吸引力, 加大了企业的流动性, 给企业营造长效的安全运行体系机制造成 了困难。

\section{2 隐患问题与原因分析}

对所调查的 300 家企业, 按照评定项 目的统计可得到表 3 所示的结果。其中, 资质证照中的消防验收意见书, 安全生产 责任制中的安全生产目标和承诺、责任制 制度, 安全生产教育培训中的培训学时, 应急救援中的预案制定、预案演练, 安全 生产记录档案, 职业卫生中的公告栏和警 示标识等评定项目, 超过 50\%的企业不合格。 对这些不合格项存在的原因, 见表 3 。 


\begin{tabular}{|c|c|c|c|c|c|}
\hline $\begin{array}{l}\text { 企业 } \\
\text { 类型 }\end{array}$ & 类型细分 & $\begin{array}{l}\text { 合 } \\
\text { 计 }\end{array}$ & $\begin{array}{l}\text { 企业 } \\
\text { 类型 }\end{array}$ & 类型细分 & $\begin{array}{l}\text { 合 } \\
\text { 计 }\end{array}$ \\
\hline $\begin{array}{c}\text { 工程 } \\
\text { 建设 } \\
\text { 类 }\end{array}$ & 公路施工企业 & 1 & \multirow{10}{*}{$\begin{array}{c}\text { 其他 } \\
\text { 类 }\end{array}$} & 仓储公司 & 5 \\
\hline \multirow{24}{*}{$\begin{array}{l}\text { 工业 } \\
\text { 生产 } \\
\text { 类 }\end{array}$} & 电气机械及器材制造企业 & 30 & & 房地产经营 & 1 \\
\hline & 纺织服装、鞋、帽制造企业 & 15 & & 金融服务企业 & 1 \\
\hline & 工艺品、日用杂品制造企业 & 2 & & 粮库粮站 & 1 \\
\hline & 供热企业 & 5 & & 其他商务服务 & 12 \\
\hline & 家具制造业 & 18 & & 企业管理服务企业 & 1 \\
\hline & $\begin{array}{c}\text { 建筑安装用金属制品制造企 } \\
\text { 业 }\end{array}$ & 10 & & 通信、计算机服务业 & 1 \\
\hline & 金属制品及搪瓷制品企业 & 10 & & 小加工企业（10 人以下） & 4 \\
\hline & $\begin{array}{c}\text { 木材加工及木、竹、藤、 } \\
\text { 棕、草制品企业 }\end{array}$ & 4 & & $\begin{array}{c}\text { 农业、林业、城市绿化及服 } \\
\text { 务企业 }\end{array}$ & 2 \\
\hline & 其他制造企业 & 19 & & 养殖企业 & 4 \\
\hline & 建材企业 & 11 & \multirow{9}{*}{$\begin{array}{c}\text { 人员 } \\
\text { 聚集 } \\
\text { 类 }\end{array}$} & 餐饮企业 $\left(100-500 \mathrm{~m}^{2}\right)$ & 1 \\
\hline & 机械企业 & 12 & & 餐饮企业（500 $\mathrm{m}^{2}$ 以上） & 11 \\
\hline & 汽车制造及配件制造企业 & 7 & & 经营性学校 & 3 \\
\hline & 燃气企业 & 15 & & $\begin{array}{c}\text { 商业零售经营单位（100- } \\
\left.1000 \mathrm{~m}^{2}\right)\end{array}$ & 1 \\
\hline & 食品制造企业 & 16 & & $\begin{array}{c}\text { 商业零售企业（1000 m² 以 } \\
\text { 上） }\end{array}$ & 2 \\
\hline & 兽药生产企业 & 2 & & 文化娱乐场所 & 6 \\
\hline & 水泥、石灰和石膏制造企业 & 4 & & 星级饭店 & 1 \\
\hline & 塑料制品企业 & 8 & & 体育运动场所 & 2 \\
\hline & $\begin{array}{c}\text { 通信设备、计算机及其他电 } \\
\text { 子设备制造企业 }\end{array}$ & 9 & & 一般性旅馆 & 7 \\
\hline & 文化用品制造企业 & 2 & \multirow{2}{*}{$\begin{array}{c}\text { 道路 } \\
\text { 交通 } \\
\text { 类 }\end{array}$} & 机动车维修 & 1 \\
\hline & 橡胶制品企业 & 2 & & 客运 & 1 \\
\hline & 医疗器械制造企业 & 7 & & & \\
\hline & 药品生产企业 & 8 & & & \\
\hline & 冶金企业 & 5 & & & \\
\hline & 印刷及包装公司 & 10 & & & \\
\hline
\end{tabular}

（1）消防验收意见

从表 3 中可以看出, 针对取得消防验 收一项, 多达 $78.67 \%$ 的企业均不合格, 且 主要集中在成立时期较早的中小企业。通 过现场与企业沟通了解, 其不合格主要原 因是由于土地规划、审批等原因。

（2）安全管理机构或人员

该类隐患主要表现在以下几个方面:

1）专 (兼) 职安全管理人员专业技能 欠缺: 由于各级部门的监管和督促, 中小 企业以文件形式任命了专 (兼) 职安全生
产管理人员，但该人员往往缺乏必需的安 全生产基本知识, 对安全生产法律法规、 标准规范、体系文件内容的不完全理解; 缺乏组织正确开展消防、用电、压力容器 等领域隐患排查的技术能力; 缺少有效组 织落实政府部门印发的关于安全生产工作 的文件的能力等 ${ }^{[4]}$, 未能切实履行安全管理 人员的职责和义务。

2) 专 (兼) 职安全管理人员配备停留 在面上: 存在专（兼）职安全管理人员的 配备停留在面上, 并未切实开展安全生产 
表 3 不合格项目分类统计

\begin{tabular}{|c|c|c|c|c|c|}
\hline \multicolumn{2}{|r|}{ 评定项目 } & \multirow{2}{*}{$\begin{array}{c}\begin{array}{c}\text { 不合格 } \\
\text { 企业比 } \\
\text { 例 }\end{array} \\
0.00 \%\end{array}$} & \multicolumn{2}{|c|}{ 评定项目 } & \multirow{2}{*}{$\begin{array}{c}\begin{array}{c}\text { 不合格 } \\
\text { 企业比 } \\
\text { 例 }\end{array} \\
28.70 \%\end{array}$} \\
\hline \multirow{2}{*}{ 资质证照 } & 营业执照 & & \multirow{3}{*}{ 其他 } & 持续改进 & \\
\hline & 消防验收意见书 & $78.67 \%$ & & 隐患排查治理工作 & $2.68 \%$ \\
\hline $\begin{array}{c}\text { 安全机构 } \\
\text { 人员 }\end{array}$ & 安全管理机构或人员 & $52.48 \%$ & & 属实性评价 & 3. $86 \%$ \\
\hline \multirow{5}{*}{$\begin{array}{l}\text { 安全生产 } \\
\text { 责任制 }\end{array}$} & 安全生产目标和承诺 & $55.10 \%$ & \multirow{4}{*}{ 场所环境 } & 建筑结构 & $2.94 \%$ \\
\hline & 责任制制度 & $53.01 \%$ & & 功能分区 & $1.94 \%$ \\
\hline & $\begin{array}{c}\text { 主要负责人或实际控制 } \\
\text { 人安全职责 }\end{array}$ & $25.71 \%$ & & 厂容厂貌 & 19. $99 \%$ \\
\hline & $\begin{array}{c}\text { 分管安全生产的负责人 } \\
\text { 安全职责 }\end{array}$ & $24.10 \%$ & & 宿舍 & $3.96 \%$ \\
\hline & 从业人员安全职责 & $21.59 \%$ & \multirow{3}{*}{ 设备设施 } & 通用要求 & $0.00 \%$ \\
\hline \multirow{2}{*}{$\begin{array}{l}\text { 规章制 } \\
\text { 度、规程 }\end{array}$} & 规章制度 & $33.17 \%$ & & 除尘 & $10.78 \%$ \\
\hline & 操作规程 & 18. $74 \%$ & & $\begin{array}{c}\text { 特种设备（通用要 } \\
\text { 求） }\end{array}$ & $32.55 \%$ \\
\hline \multirow{5}{*}{$\begin{array}{l}\text { 安全生产 } \\
\text { 教育培训 }\end{array}$} & 培训计划 & $35.33 \%$ & \multirow{6}{*}{ 消防安全 } & 消防设施和器材 & $28.16 \%$ \\
\hline & 培训学时要求 & $66.15 \%$ & & 消防通道 & $0.00 \%$ \\
\hline & 培训内容 & $33.13 \%$ & & 安全出口 & $3.55 \%$ \\
\hline & 培训档案 & $34.52 \%$ & & 消防控制室 & $4.86 \%$ \\
\hline & 相关人员证件 & $26.29 \%$ & & 疏散标志 & $23.88 \%$ \\
\hline \multirow{4}{*}{$\begin{array}{l}\text { 应急 } \\
\text { 救援 }\end{array}$} & 预案制定 & $72.25 \%$ & & 应急照明 & $23.91 \%$ \\
\hline & 组织建立 & $11.20 \%$ & \multirow{3}{*}{ 用电安全 } & 保护系统 & $4.86 \%$ \\
\hline & 预案演练 & $52.48 \%$ & & 通用要求 & $52.38 \%$ \\
\hline & 应急救援器材 & $40.12 \%$ & & 配电箱 & $14.86 \%$ \\
\hline \multirow{6}{*}{$\begin{array}{l}\text { 职业卫生 } \\
\text { 基础管理 }\end{array}$} & 基本要求 & $16.98 \%$ & \multirow{3}{*}{$\begin{array}{l}\text { 危险化学 } \\
\text { 品管理 }\end{array}$} & 基本要求 & 7. $29 \%$ \\
\hline & $\begin{array}{c}\text { 职业病危害防治制度和 } \\
\text { 操作规程 }\end{array}$ & $28.63 \%$ & & 储存 & $9.77 \%$ \\
\hline & 职业病危害培训 & $32.46 \%$ & & 使用 & $3.57 \%$ \\
\hline & 职业病危害告知 & $21.40 \%$ & \multirow{4}{*}{$\begin{array}{l}\text { 职业卫生 } \\
\text { 现场管理 }\end{array}$} & 车间布局 & $9.27 \%$ \\
\hline & 职业病危害因素检测 & $30.33 \%$ & & 公告栏 & $38.85 \%$ \\
\hline & 职业卫生档案 & $34.99 \%$ & & 警示标志 & $42.63 \%$ \\
\hline \multirow{2}{*}{$\begin{array}{l}\text { 资金 } \\
\text { 保障 }\end{array}$} & 安全投入 & $13.71 \%$ & & 职业病防护设施 & $23.86 \%$ \\
\hline & 相关保险 & $16.46 \%$ & \multirow[b]{2}{*}{ 有限空间 } & 检测 & 7. $14 \%$ \\
\hline $\begin{array}{l}\text { 相关方管 } \\
\text { 理 }\end{array}$ & 相关方管理 & $18.99 \%$ & & 现场监督管理 & $8.33 \%$ \\
\hline \multirow[t]{2}{*}{ 记录档案 } & 安全生产记录档案 & $75.16 \%$ & \multirow{2}{*}{ 操作行为 } & 从业人员作业 & 4. $67 \%$ \\
\hline & & & & 劳动防护用品使用 & $25.10 \%$ \\
\hline
\end{tabular}

隐患排查、风险管理等工作。

3 ) 存在企业的安全生产管理工作未形 成系统性, 未在全员中形成良好的安全生
产文化氛围, 过度依赖于专（兼）职安全 生产管理人员。当专 (兼) 职安全管理人 员发生离职或变动时, 往往造成企业的各 
项安全生产管理体系无法正常运行, 从而 出现安全生产管理工作的不可持续性, 安 全生产隐患排查工作的断档, 增加事故发 生的可能性。

\section{（3）安全生产责任制}

建立安全生产责任制其目的是增强企 业各级领导、各职能部门及其工作人员和 岗位生产人员在安全生产中应履行的职责 和应承担的责任, 充分调动各级人员和部 门在安全生产方面的积极性和主观能动性, 确保安全生产的一项重要的手段。通过现 场检查发现, 企业安全生产责任制存在的 主要问题包括：责任制内容与岗位实际职 责不一致、责任制内容千篇一律、形式大 于实际等。

\section{（4）安全生产教育培训}

岗前教育培训是《安全生产法》等法 律法规的明确要求, 通过对调查企业安全 生产教育培训存在的问题进行再总结, 主 要集中于对于新员工的岗前安全生产教育 培训, 主要表现在:

1) 企业重视领导班子、特种设备作业 人员和特种作业人员的安全教育培训, 忽 视对一线人员的岗前安全教育培训;

2) 岗前教育培训内容形式单一化、缺 乏针对性, 未能按照法律法规要求, 对安 全生产法律法规、企业的安全生产管理体 系, 尤其是岗位的安全生产特点进行宣贯、 培训, 达不到岗前安全教育培训的效果;

3) 岗前安全教育培训考核工作纸面化。 考核工作最直接的体现是考核试卷, 但通 过检查发现, 培训试卷的内容设计与培训 教育内容、生产经营实际相脱节; 考核试 卷存在笔迹一致, 代填现象。企业并未将 岗前安全教育培训考核合格作为用人、定 岗的重要参考。

其他人员的培训问题主要体现在:

1) 对 “经验” 的迷信。“多年来一直 这么干，也没发生事故”在一线从业人员 脑海中根深蒂固, 对企业一直强调的安全 生产管理制度, 安全操作规程置若罔闻;

2) 对自身权利的不尊重。表现为从业 人员不了解国家法律法规所赋予的安全生 产的权利, 不了解企业应当为一线从业人
员提供的安全生产保障服务, 不掌握在涉 及安全生产时正确处置维护利益的方式等 等;

3) 不了解企业及岗位所存在的危险有 害因素和可能发生的事故类型, 不掌握突 发事件发生后的紧急逃生技能和逃生方式。

除此, 主要负责人等中小企业多存在 忽视或不重视安全生产教育培训, 不积极、 主动、按时参加安全生产教育培训等问题。 (5) 应急救援

通过现场检查发现, 现阶段中小企业 基本具备了要求的应急预案、应急演练记 录, 配备了必要的应急救援物资, 但对其 进行剖析, 在应急预案和应急演练方面存 在较大缺失。

1) 应急预案从根本上不符合国家相关 标准规范要求, 或符合要求但内容笼统、 针对性差。如应急预案内容并未建立在对 企业危险源进行充分识别和对事故类型进 行有效剖析的基础上, 对事故的发生不能 给出具体的应对措施;

2) 中小企业的应急预案往往作为应对 各类安全生产检查工作的纸质性文件, 部 分企业的应急预案有两套或多套, 但均深 藏柜底, 从根本上没有作为处置突发事件 的指导文件, 没有对预案涉及人员进行培 训宣贯, 所涉人员不了解突发事件处置工 作中的具体职责, 部分企业的主要负责人 (应急预案文本中的总指挥) 甚至不知应 急预案的概念和存在;

3) 中小企业所开展的应急演练工作多 为消防灭火器材正确使用的培训教育, 且 历年历次应急演练内容大同小异, 并未根 据预案规定的应急处置措施有效开展, 未 能起到检验预案、完善准备、锻炼队伍、 磨合机制的根本作用;

4）应急演练能够做到每年定期开展, 但演练内容单一, 多等同于灭火器材的使 用方法的培训, 形式大于实效, 无法实现 应急演练的检验预案、锻炼队伍、磨合机 制的作用。

(6) 用电安全

“电”对于各级规模、各类性质的生 产经营企业的正常生产经营均是必不可少 
的。鉴于过往统计, 电气火灾在多年的火 灾事故统计中, 约占三成左右, 是火灾发 生的主要原因。且造成电气火灾的原因多 种多样, 包括短路、过载、接触不良、静 电等, 且电气线路、电气设备广泛存在于 中小企业, 稍有不慎, 即造成了安全隐患 的存在 ${ }^{[5]}$ 。对现场检查发现的电气隐患主要 为:

1）企业内安全生产管理人员缺乏电气 安全基本知识, 无法实现对电气隐患的定 期排查;

2）中小企业在生产现场多多少少存在 私拉乱改的电气线路;

3）生产设备的接地、电气开关的漏电 保护存在较多问题隐患;

4）电气线路相线颜色使用错误, 尤其 是地线未正确使用黄绿相间的颜色;

5) 大量存在配电开关箱内有积尘、箱 体被遮挡, 电气线路穿过墙面未加装套管;

6）大量存在 “一闸多机” 现象, 未切 实做到 “一机一闸一漏保”。

（7）液化石油气使用

由于液化石油气的易燃易爆性, 以及 近些年来液化石油气钢瓶发生的起火爆炸 事故, 都给液化石油气的安全规范使用敲 响了警钟。通过现场检查发现, 液化石油 气大量应用与中小企业的食堂, 液化石油 气使用隐患广泛覆盖了中小企业。

主要问题包括: 未按要求设置独立的 气瓶间; 气瓶间内的电气设备设施不防爆; 未按要求设置液化石油气泄漏报警装置; 所使用的液化石油气钢瓶不合格; 液化石 油气连接软管长度、软管质量、软管穿墙 套管不合格; 液化石油气钢瓶距与灶台间 距不足等等。

\section{4. 对策和建议}

针对在中小企业安全生产检查中发现 的主要和突出问题, 笔者结合安全生产工 作实践给出如下对策和建议措施:

（1）对企业专 (兼) 职安全生产管理 人员的任职能力进行严格把关。安全生产 监督管理部门在各类检查工作中, 要着重 突出对企业专 (兼) 职安全生产能力、水 平的检查, 且多采用口头提问的形式进行。
检查内容要重点包含安全生产法律法规、 企业危险有害因素、应急管理、现场隐患 排查、岗位安全操作规程等与企业安全生 产运行切实相关的内容。

（2）安全生产监督管理部门在安全检 查过程中要尽力摒弃对照检查表进行打分, 分数合格即为通过的方式。安全生产隐患 无小事, 一个小小的烟头往往酿成弥天大 祸。要根据实际, 对检查发现的各项隐患 问题均设置整改期限, 严格按照整改期限 要求, 对企业进行督促整改。

（3）针对广泛存在的液化石油气使用 方面的问题隐患, 一是要加强对液化石油 气供气站所售钢瓶和气质的抽查检查, 同 时督促其对购气用户做好安全用气的宣传 教育; 二是要开展液化石油气使用场所的 安全抽查、检查工作。针对隐患类型多、 数量大的电气安全领域, 要多线共进, 一 方面要加大对企业从业人员专项培训的力 度; 另一方面要提高电工作业取证的门槛, 提升电工作业的专业技能水平; 三是要充 分发动专业社会组织参与到电气隐患排查 治理工作中来。

（4）广泛利用社会安全生产组织, 细 分安全生产培训课程, 提高安全生产教育 培训工作的针对性和实效性。同时, 细分 安全生产监管网格, 在网格中树立安全生 产工作典型, 以点带面, 提升企业的安全 生产管理水平。

（5）在现有对应急管理检查内容的基 础上, 提高应急预案检查要求, 提升应急 预案在企业突发事件处置过程中的地位和 作用; 提高应急演练检查要求, 推动落实 应急演练在应急管理工作中的重要作用。

（6）创新安全监管手段方法。首先, 针对安全生产, 中小企业经营决策权的高 度集中, 即是劣势又是优势。做好中小企 业的安全生产工作, 要充分发挥好其优势, 通过培训、座谈、奖励与惩罚, 合理引导 和提升主要负责人的安全意识, 为主要负 责人加强企业安全生产管理工作出谋划策。 其次, 根据中小企业区域、行业属性、规 模等内容细分网格, 加强精细化管理, 摒 弃一张检查标、一套安全体系要求全覆盖, 
或企业多体系重复建设。第三, 要加强对 检查发现问题隐患的整改工作复查, 提升 检查工作效率。第四, 加强各部门间的横 向沟通, 实现企业基本信息的有机共享, 有效发挥既有资源的作用 ${ }^{[6][7]}$ 。

（7）突出信息化的重要辅助作用。充 分利用大数据、物联网等信息化手段, 加 强对中小企业安全生产状况的调研、统计 分析, 有效指导安全监管和应急救援力量 投放; 充分利用手机、平板电脑等移动终 端, 以及广大传统媒体进行宣传培训、业 务指导, 提升全民的安全生产意识和能力。

\section{Acknowledgements}

This study was supported by Support for the Training of Excellent Talents in Beijing (No. 2015400685627G239).

\section{致谢}

本研究得到了北京市优秀人才培养资助 (2015400685627G239) 的资助。

\section{参考文献}

[1] Zongzhi Wu, Shengzhu Zhang, Mingrong Zeng, Analytical research on the accident risk in three industries of China And USA in the period of 2006-2010, Journal of Risk Analysis and Crisis Response, 3(1) : 52-58, 2013.

[2] 熊卫,左凯, 发展我国中小企业的重要性 及政策建议, 武汉工业学院学报, (4) : 52-55, 2000.

[3] 杨兰天, 中小企业安全管理存在的问题 及策略研究, 企业改革与管理, 61, 2017.

[4] 陆玉梅, 梅强, 中小企业安全管理现状 调查与对策研究, 中国安全科学学报(6): 86-91, 2006.

[5] 刘东旗, 刘艳芹,陈宁, 电气火灾的分析 和预防, 中国安全生产科学技术, 7(7): 179-182, 2011.

[6] 黄晓丰, 中小企业安全生产工作存在的 问题及对策措施, 中国职业安全健康协 会 2010 年学术年会论文集, 煤炭工业 出版社, 北京, 2010 .

[7] 刘霞, 中小企业安全监管对策研究— 以昆明市为例, 江大学, 浙江, 2008. 